ARTICLE

https://doi.org/10.1038/s41467-019-10302-0

\title{
Double-shelled hollow rods assembled from nitrogen/sulfur-codoped carbon coated indium oxide nanoparticles as excellent photocatalysts
}

\author{
Liming Sun (1) ${ }^{1,3}$, Rong Li, ${ }^{1,3}$, Wenwen Zhan (1) ${ }^{1}$, Yusheng Yuan ${ }^{1}$, Xiaojun Wang (1) ${ }^{1}$, Xiguang $\operatorname{Han}^{1}$ \& \\ Yanli Zhao (1) ${ }^{2}$
}

Excellent catalytic activity, high stability and easy recovery are three key elements for fabricating efficient photocatalysts, while developing a simple method to fabricate such photocatalysts with these three features at the same time is highly challenging. In this study, we successfully synthesized double-shelled hollow rods (DHR) assembled by nitrogen (N) and sulfur (S)-codoped carbon coated indium(III) oxide $\left(\mathrm{In}_{2} \mathrm{O}_{3}\right)$ ultra-small nanoparticles (N,S-C/ $\mathrm{In}_{2} \mathrm{O}_{3}$ DHR). N,S-C/ $/ \mathrm{n}_{2} \mathrm{O}_{3}$ DHR exhibits remarkable photocatalytic activity, high stability and easy recovery for oxidative hydroxylation reaction of arylboronic acid substrates. The catalyst recovery and surface area were well balanced through improved light harvesting, contributed by concurrently enhancing the reflection on the outer porous shell and the diffraction in the inside double-shelled hollow structure, and increased separation rate of photogenerated carriers. Photocatalytic mechanism was investigated to identify the main reactive species in the catalytic reactions. The electron separation and transfer pathway via N,S-codoped graphite $/ \mathrm{In}_{2} \mathrm{O}_{3}$ interface was revealed by theoretical calculations.

\footnotetext{
${ }^{1}$ Jiangsu Key Laboratory of Green Synthetic Chemistry for Functional Materials, Department of Chemistry, School of Chemistry and Materials Science, Jiangsu Normal University, Xuzhou 221116, P. R. China. ${ }^{2}$ Division of Chemistry and Biological Chemistry, School of Physical and Mathematical Sciences, Nanyang Technological University, 21 Nanyang Link, Singapore 637371, Singapore. ${ }^{3}$ These authors contributed equally: Liming Sun, Rong Li. Correspondence and requests for materials should be addressed to X.H. (email: xghan@jsnu.edu.cn) or to Y.Z. (email: zhaoyanli@ntu.edu.sg)
} 
P hotoredox catalysis is a highly promising route to solar-tochemical energy conversion in the form of organic synthesis under relatively mild conditions ${ }^{1-9}$. Among numerous photocatalysts studied in recent decades, indium oxide $\left(\mathrm{In}_{2} \mathrm{O}_{3}\right)$ with narrow bandgap $(\sim 2.8 \mathrm{eV})$, high optical transparency, excellent stability, and suitable band potentials (including valence band (VB) and conduction band (CB)) to induce redox reactions has attracted much attention as a visible-light-induced photocatalyst ${ }^{10-15}$. Compared with bulk $\mathrm{In}_{2} \mathrm{O}_{3}$, granular $\operatorname{In}_{2} \mathrm{O}_{3}$ nanoparticles have large surface areas, so they contain more active sites and display improved photocatalytic activity ${ }^{16-18}$. However, $\mathrm{In}_{2} \mathrm{O}_{3}$ nanoparticles still possess two undesirable disadvantages, i.e., the fast recombination of photogenerated carriers ${ }^{19}$ and the hard recovery in solution, which suppress their practical applications in photocatalytic field. Therefore, a rational design of nanosized granular $\mathrm{In}_{2} \mathrm{O}_{3}$ with high reactivity and easy recovery is highly desirable for extending their applications.

One effective approach to achieve the above-mentioned target is to assemble carbon-coated $\operatorname{In}_{2} \mathrm{O}_{3}$ nanoparticles into the superstructure with regular morphology and large size. On account of excellent mobility of charge carriers, the carbon layer can act as photogenerated electron acceptor to improve the separation efficiency of photogenerated carriers ${ }^{20-22}$. In particular, N,S-codoping sites with induced structure defects in carbon framework could increase the electron delocalization, further enhancing the separation efficiency of electrons and holes ${ }^{23-25}$. Thus, integrating N,S-codoped carbon layer with $\operatorname{In}_{2} \mathrm{O}_{3}$ nanoparticles would effectively enhance the photocatalytic activity. Moreover, assembling the resulted N,S-codoped carbon-coated $\mathrm{In}_{2} \mathrm{O}_{3}$ nanoparticles into the superstructure may facilitate the recovery of photocatalysts. However, there are two bottlenecks in this approach for fabricating efficient $\mathrm{In}_{2} \mathrm{O}_{3}$ photocatalysts. Firstly, it is difficult to control the coating of a carbon layer and introduce double heteroatoms into the carbon layer. In general, sufficient and intimate contact interface is the key factor to ensure efficient transfer of photogenerated carriers. However, most of the reported carbon materials as the substrate loaded on metal oxide nanoparticles had insufficient carbon/nanoparticle interface ${ }^{26}$. Uniformly coating a carbon layer on metal oxide nanoparticles is still a challenging task. In addition, conventional approaches for introducing heteroatoms into carbon materials have some unavoidable disadvantages, such as toxic precursors, special and/or sophisticated instruments, harsh conditions, and uneven distribution of doped atoms ${ }^{27-30}$. Realizing the co-doping of two types of heteroatoms is even harder. Therefore, it is highly needed to overcome the challenge toward fabricating ultrafine metal oxide nanoparticles coated by co-doped carbon layers. Secondly, it is difficult to balance the ease of photocatalyst recovery with the surface area. Although assembling N,S-codoped carbon-coated $\mathrm{In}_{2} \mathrm{O}_{3}$ ultrafine nanoparticles into photocatalysts with regular morphology and large size is a straightforward method to solve the problem of difficult recycling ${ }^{31,32}$, this solution would result in the decreases of surface areas, reactive sites and photocatalytic activity. Therefore, it is necessary to balance the effects of photocatalyst recovery and surface area by improving other factors affecting photocatalytic activity. To address these issues, we developed a promising approach to fabricate efficient photocatalysts assembled from N,S-codoped carbon uniformly coated $\mathrm{In}_{2} \mathrm{O}_{3}$ nanoparticles, aiming to achieve excellent catalytic activity and easy recovery at the same time.

Herein, double-shelled hollow rods (DHRs) assembled by N,Scodoped carbon uniformly coated $\mathrm{In}_{2} \mathrm{O}_{3}$ ultrafine nanoparticles $\left(\mathrm{N}, \mathrm{S}-\mathrm{C} / \mathrm{In}_{2} \mathrm{O}_{3}\right.$ DHR) were synthesized using a porous metal organic framework (MOF), i.e., MIL-68-In, as the template and 1,2-benzisothiazolin-3-one (BIT) as the modulator in one step. Since the carbon atom disperses homogeneously in the MOF structure at a molecular level ${ }^{33-42}$, the carbon layer in N,S-C/ $\mathrm{In}_{2} \mathrm{O}_{3}$ DHR is uniformly distributed on the $\mathrm{In}_{2} \mathrm{O}_{3}$ surface to produce intimately contacted core-shell structure and maximize the interaction between the components, facilitating the separation of charge carriers. The obtained N,S-C/ $/ \mathrm{In}_{2} \mathrm{O}_{3}$ DHR could be recycled from the solution through simple centrifugation. Moreover, N,S-C/ $/ \mathrm{In}_{2} \mathrm{O}_{3}$ DHR performs remarkably in catalyzing a series of arylboronic acids under light irradiation. The photocatalytic time of $\mathrm{N}, \mathrm{S}-\mathrm{C} / \mathrm{In}_{2} \mathrm{O}_{3}$ DHR required to achieve $99 \%$ yield was only half of the time needed by recently reported $\mathrm{N}$-doped carbon-coated dodecahedral $\mathrm{In}_{2} \mathrm{O}_{3}\left(\mathrm{~N}-\mathrm{C} / \mathrm{In}_{2} \mathrm{O}_{3} \mathrm{HD}\right)^{43}$. In addition, the as-prepared $\mathrm{N}, \mathrm{S}-\mathrm{C} / \mathrm{In}_{2} \mathrm{O}_{3}$ DHR exhibits high photocatalytic activity under green ( $3 \mathrm{~W}$ LED lamp, $525 \mathrm{~nm}$ ) and yellow ( $3 \mathrm{~W}$ LED lamp, $590 \mathrm{~nm}$ ) lights, indicating that it broadens the response range of light to wider wavelength. This observation is of great significance for expanding the practical application of $\mathrm{In}_{2} \mathrm{O}_{3}$-based materials. However, $\mathrm{N}-\mathrm{C} / \mathrm{In}_{2} \mathrm{O}_{3} \mathrm{HD}$ did not show any photocatalytic activity under green and yellow lights ${ }^{43}$. These comparison results suggest the importance of N,S-codoping for improving the photocatalytic activity of carbon-coated photocatalysts. Benefiting from the simultaneously increased reflection on the outer shell and diffraction on the hollow cavity of the N,Scodoped double-shelled hollow structure, and the enhanced separation rate of photogenerated carriers, the photocatalyst recovery and surface area were well balanced. The mechanism for the enhanced separation efficiency of photogenerated carriers by N,S codoping was clarified by theoretical calculations, i.e., the hybridization of $\mathrm{N} 2 \mathrm{p}, \mathrm{S} 3 \mathrm{p}$ and $\mathrm{C} 2 \mathrm{p}$ increases the strength of interstitial states to further improve the transfer and separation efficiency of photogenerated carriers. We also investigated photocatalytic mechanism of the oxidative hydroxylation and confirmed the key active radical of this system in the photocatalysis. Finally, the microscopic pathway for the separation and migration of carriers in $\mathrm{N}, \mathrm{S}-\mathrm{C} / \mathrm{In}_{2} \mathrm{O}_{3} \mathrm{DHR}$ was revealed by theoretical calculations.

\section{Results}

Structure and composition of the photocatalysts. The preparation of monodispersed double-shelled hollow rods (N,S-C/ $\mathrm{In}_{2} \mathrm{O}_{3}$ DHR) assembled by N,S-codoped carbon-coated $\mathrm{In}_{2} \mathrm{O}_{3}$ ultrafine nanoparticles is schematically shown in Fig. 1. The experimental details are presented in the Supporting Information. During the synthetic process, BIT acted a modulator to control the growth of MIL-68-In crystals from indium metal ion and $p$ phthalic acid ligand, resulting in the formation of N,S-codoped MIL-68-In with the rod morphology. The length-width ratio of N,S-codoped MIL-In-68 rods could be controlled by adding different amounts of $\mathrm{BIT}^{44,45}$. Upon increasing the amount of BIT, the length-width ratio of N,S-codoped MIL-In-68 rods gradually decreases (Supplementary Fig. 1). A subsequent high-temperature annealing treatment of N,S-codoped MIL-68-In with the largest length-width ratio in vacuum atmosphere leads to the formation of N,S-C/ $/ \mathrm{In}_{2} \mathrm{O}_{3}$ DHR. Typical diffraction peaks in the powder Xray diffraction (XRD) pattern (Supplementary Fig. 2a) of N,Scodoped MIL-68-In can be well indexed to phase-pure MIL-68In, which are in good agreement with simulated ones. Scanning electron microscopy (SEM) images of N,S-codoped MIL-68-In at different magnifications are shown in Fig. 2a. The size of N,Scodoped MIL-68-In crystals is $0.4-1.2 \mu \mathrm{m}$ in width and $5-9 \mu \mathrm{m}$ in length (Supplementary Fig. 3). Moreover, these N,S-codoped MIL-68-In crystals are highly monodispersed, showing welldefined rod morphology with smooth surface.

Notably, the BIT molecule provides copious $\mathrm{N}$ and $\mathrm{S}$ elements into MIL-68-In for enabling the creation of $\mathrm{N}$ and $\mathrm{S}$ codoped materials. To check the existence of $\mathrm{N}$ and $\mathrm{S}$ elements in 


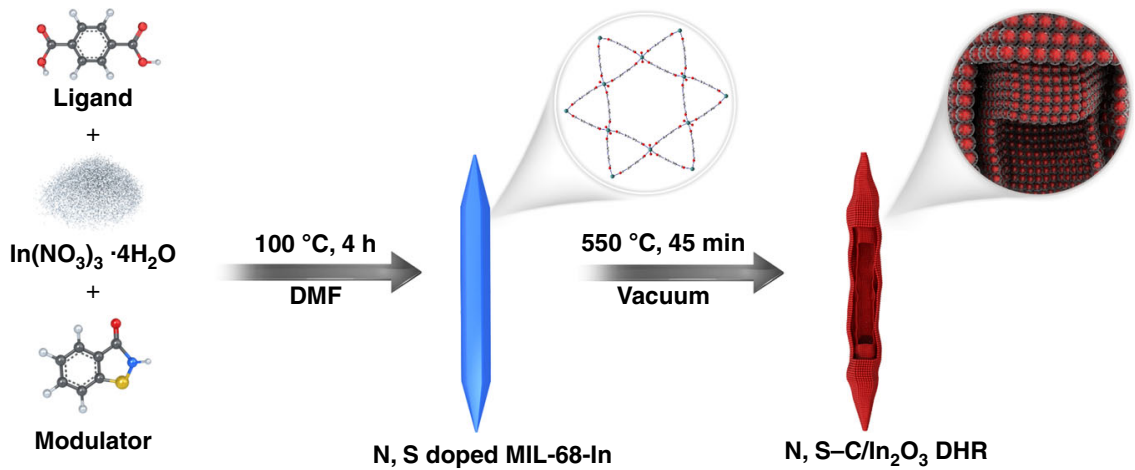

Fig. 1 Schematic illustration showing the synthetic process of monodispersed $\mathrm{N}, \mathrm{S}-\mathrm{C} / \mathrm{In}_{2} \mathrm{O}_{3}$ DHR

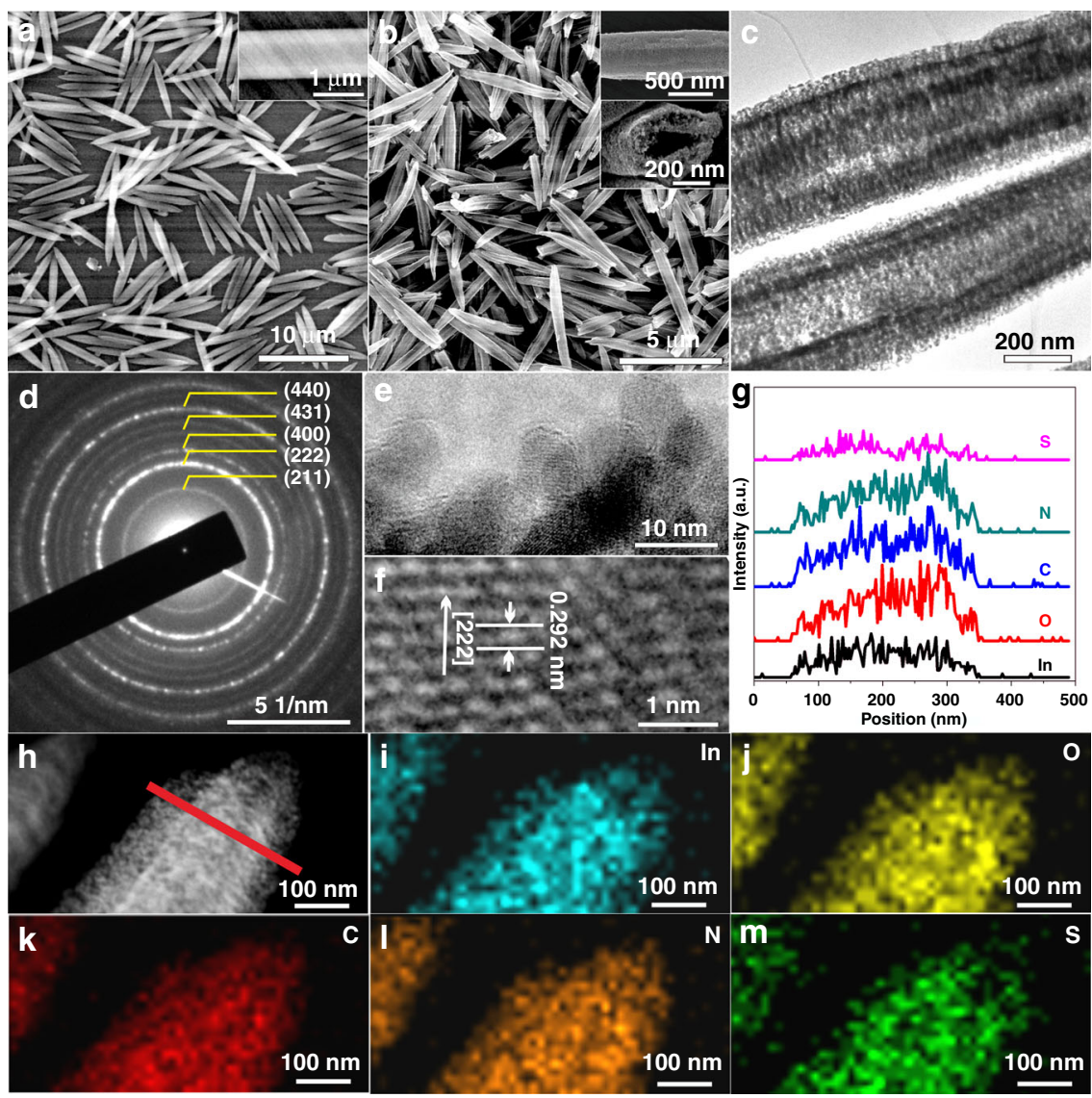

Fig. 2 Morphology and structural characterizations. a SEM image of N,S-codoped MIL-68-In. b SEM images, c TEM image, d Corresponding SAED pattern, e Local enlarged TEM image, $\mathbf{f}$ HRTEM image, $\mathbf{g}$ Elemental profiles, h STEM image, and i-m EDX elemental mapping of In, O, C, N, and S for N,S-C/In ${ }_{2} \mathrm{O}_{3}$ DHR. Source data are provided as a Source Data file

MIL-68-In, the energy-dispersive X-ray (EDX) mapping of N,Scodoped MIL-68-In was measured to investigate the element distributions. The corresponding EDX maps of In, $\mathrm{O}, \mathrm{C}, \mathrm{N}$, and $\mathrm{S}$ elements (Supplementary Fig. 4) indicate that all these elements are well dispersed in MIL-68-In. The thermal stability of N,Scodoped MIL-68-In is investigated by thermogravimetric analysis (TGA, Supplementary Fig. 5). According to the TGA curve, initial $6.7 \%$ weight lost between 400 and $500^{\circ} \mathrm{C}$ can be ascribed to the adsorbed and coordinated solvent molecules, and the steep weight loss (about 55.5\%) is due to the carbonization of N,S-codoped MIL-68-In. Hence, annealing N,S-codoped MIL-68-In at $550^{\circ} \mathrm{C}$ in a vacuum atmosphere is sufficient to ensure complete conversion from MIL-68-In to $\mathrm{In}_{2} \mathrm{O}_{3}$.
Crystalline structure of the annealed product $\left(\mathrm{N}, \mathrm{S}-\mathrm{C} / \mathrm{In}_{2} \mathrm{O}_{3}\right.$ DHR) was explored by powder XRD (Supplementary Fig. 2b). All of the diffraction patterns correspond well with the cubic $\operatorname{In}_{2} \mathrm{O}_{3}$ (JCPDS card number 00-006-0416), indicating that the N,Scodoped MIL-68-In precursor is transformed to cubic $\operatorname{In}_{2} \mathrm{O}_{3}$ during the annealing treatment. The SEM image (Fig. 2b) indicates that the overall rod morphology of MIL-68-In is well preserved with $0.5-0.8 \mu \mathrm{m}$ in width and $5-8 \mu \mathrm{m}$ in length (Supplementary Fig. 6). The size of the annealed product is slightly smaller than that of N,S-codoped MIL-68-In, which is mainly attributed to partial collapse of MOF skeleton and the carbonization of organic ligand and modulator during the transformation process. The magnified observation (insert of 
Fig. 2b) reveals the micro-rod morphology with a double-shelled hollow structure, resulted from heterogeneous decomposition of the MIL-68-In MOF during the annealing process. The exterior MOF materials firstly decompose to form an $\operatorname{In}_{2} \mathrm{O}_{3}$ outer shell, and then the inner MOF structure is gradually carbonized under prolonged pyrolysis on account of large temperature gradient from the surface to the inner structure.

More structural details of double-shelled micro-rods are revealed by transmission electron microscopy (TEM). The low magnification TEM image (Fig. 2c) shows obviously brighter contrast, which demonstrates the double-shelled feature and porous nature of the resulting $\mathrm{N}, \mathrm{S}-\mathrm{C} / \mathrm{In}_{2} \mathrm{O}_{3} \mathrm{DHR}$, corresponding well with the SEM observations. The well-defined rings of electron diffraction pattern (Fig. 2d) confirm the polycrystallinity of $\mathrm{In}_{2} \mathrm{O}_{3}$ rods. A high-magnification TEM survey (Fig. 2e) from a typical sample area shows that the porous rod structure of N,S-C/ $\mathrm{In}_{2} \mathrm{O}_{3}$ DHR is really constituted by individual nanoparticles with the diameter about $10 \mathrm{~nm}$. The TEM image also clearly exhibits a continuous carbon layer covered on the entire surface of nanoparticles. The surface carbon layer can increase the electrical conductivity of $\mathrm{In}_{2} \mathrm{O}_{3}$ nanoparticles, and thus improves the separation efficiency of photogenerated carriers. In addition, the external carbon layer can block the aggregation and increase the stability of the nanoparticles. Clear lattice fringes were observed from the high-resolution TEM (HRTEM) image (Fig. 2f), where $0.292 \mathrm{~nm}$ is assigned to the (222) interplane spacing of cubic $\mathrm{In}_{2} \mathrm{O}_{3}$, further confirming the cubic $\mathrm{In}_{2} \mathrm{O}_{3}$ phase of the nanoparticles. The presence of the In, $\mathrm{C}, \mathrm{O}, \mathrm{S}$, and $\mathrm{N}$ elements in $\mathrm{N}, \mathrm{S}-\mathrm{C} / \mathrm{In}_{2} \mathrm{O}_{3}$ DHR was proven by elemental distribution analysis, including the elemental line profiles (Fig. 2g) and elemental mapping. Scanning transmission electron microscopy (STEM) image indicates that the double-shelled structure of the $\mathrm{In}_{2} \mathrm{O}_{3}$ rods is indeed built by small nanoparticles (Fig. 2h). The elemental mapping results (Fig. $2 \mathrm{i}-\mathrm{m}$ ) demonstrate the uniform distribution of the In, C, O, S, and $\mathrm{N}$ within the $\mathrm{N}, \mathrm{S}-\mathrm{C} / \mathrm{In}_{2} \mathrm{O}_{3}$ DHR structure.

During the pyrolysis, the indium ion in the MIL-68-In microrods is converted to $\mathrm{In}_{2} \mathrm{O}_{3}$ nanoparticles, and the external N,Scodoped carbon layer is formed by in situ carbonization. Therefore, the final annealed product is N,S-codoped carboncoated $\mathrm{In}_{2} \mathrm{O}_{3}$ ultra-small nanoparticles with DHR morphology. The porous feature of N,S-C/ $\mathrm{In}_{2} \mathrm{O}_{3}$ DHR was investigated by $\mathrm{N}_{2}$ adsorption/desorption isotherms (Supplementary Fig. 7). The Brunauer-Emmett-Teller (BET) measurements give a specific surface area of $37.6 \mathrm{~m}^{2} / \mathrm{g}$, and the Barrett-Joyner-Halenda (BJH) pore size distribution is mainly centered at about $10-50 \mathrm{~nm}$ (insert of Supplementary Fig. 7). These results confirm that the N, $\mathrm{S}-\mathrm{C} / \mathrm{In}_{2} \mathrm{O}_{3}$ DHR obtained by the calcination of $\mathrm{N}, \mathrm{S}$-codoped MIL-68-In in vacuum atmosphere has DHR morphology with a mesoporous structure.

Chemical states of elements in the N,S-C/ $\operatorname{In}_{2} \mathrm{O}_{3}$ DHR were measured by X-ray photoelectron spectroscopy (XPS). The survey spectrum (Fig. 3a) indicates the existence of In, O, N, S, and $\mathrm{C}$ elements in $\mathrm{N}, \mathrm{S}-\mathrm{C} / \mathrm{In}_{2} \mathrm{O}_{3}$ DHR. The high-resolution XPS spectrum of In $3 \mathrm{~d}$ shows two peaks corresponding to In $3 \mathrm{~d}_{3 / 2}$ and In $3 \mathrm{~d}_{5 / 2}$ (Fig. 3b). Higher binding energy at $444.5 \mathrm{eV}$ corresponds to In $3 \mathrm{~d}_{5 / 2}$ of $\operatorname{In}_{2} \mathrm{O}_{3}$, and the peak at $452.1 \mathrm{eV}$ is in agreement with In $3 \mathrm{~d}_{3 / 2}$ of $\operatorname{In}_{2} \mathrm{O}_{3}$. The high-resolution spectrum of $\mathrm{O} 1 \mathrm{~s}$ displays an asymmetric curve (Fig. $3 \mathrm{c}$ ), which consists of three peaks corresponding to three kinds of oxygen in N,S-C/ $\mathrm{In}_{2} \mathrm{O}_{3}$ DHR. The three peaks at $529.8 \mathrm{eV}\left(\mathrm{O}_{\mathrm{L}}\right), 530.6 \mathrm{eV}\left(\mathrm{O}_{\mathrm{V}}\right)$ and $531.8 \mathrm{eV}\left(\mathrm{O}_{\mathrm{C}}\right)$ are assigned to lattice oxygen, oxygen-deficient region, and chemisorbed oxygen species (e.g., hydroxyl species), respectively ${ }^{31,46}$. The $C 1$ s high-resolution spectrum (Fig. $3 \mathrm{~d}$ ) can be coherently fitted by five major peaks, assigning to $\mathrm{C}=\mathrm{O}$ bonds $(288.9 \mathrm{eV}), \mathrm{C}-\mathrm{O}$ bonds $(286.8 \mathrm{eV}), \mathrm{C}-\mathrm{N}$ bonds $(285.8 \mathrm{eV}), \mathrm{C}=\mathrm{C}$ bonds $(284.9 \mathrm{eV})$ and $\mathrm{C}-\mathrm{S}$ bonds $(284.2 \mathrm{eV})$. The existence of nitrogen elements in the $\mathrm{N}, \mathrm{S}-\mathrm{C} / \mathrm{In}_{2} \mathrm{O}_{3}$ DHR structure is mainly ascribed to the $\mathrm{N}$-graphene (Fig. $3 \mathrm{e}$ ), which is also supported by $\mathrm{C} 1 \mathrm{~s}$ spectrum. The S $2 \mathrm{p}$ spectrum (Fig. $3 \mathrm{f}$ ) can be deconvoluted into two peaks, assigning to $\mathrm{S}-\mathrm{C}(167.3 \mathrm{eV}$ and $168.4 \mathrm{eV})$. These results further confirm that the $\mathrm{N}, \mathrm{S}-\mathrm{C} / \mathrm{In}_{2} \mathrm{O}_{3} \mathrm{DHR}$ is comprised of $\mathrm{In}_{2} \mathrm{O}_{3}$ coated by the N,S co-doped carbon layer. The $\mathrm{N}$ and $\mathrm{S}$ co-doping could improve the electronic transport efficiency and chemical activity of the carbon layer, which could in turn enhance the separation efficiency of carriers in photocatalytic reactions.

Photophysical properties of the photocatalysts. The first step of photocatalysis is the generation of electron-hole pairs under light irradiation. Thus, the UV-vis absorption spectrum of the obtained $\mathrm{N}, \mathrm{S}-\mathrm{C} / \mathrm{In}_{2} \mathrm{O}_{3}$ DHR was measured and compared with that of $\mathrm{N}, \mathrm{S}-\mathrm{C} / \mathrm{In}_{2} \mathrm{O}_{3} \mathrm{NP}\left(\mathrm{In}_{2} \mathrm{O}_{3}\right.$ nanoparticles coated by N,Scodoped carbon, Supplementary Fig. 8), N-C/ $\operatorname{In}_{2} \mathrm{O}_{3} \mathrm{NP}\left(\mathrm{In}_{2} \mathrm{O}_{3}\right.$ nanoparticles coated by $\mathrm{N}$-doped carbon, Supplementary Fig. 9), $\mathrm{In}_{2} \mathrm{O}_{3}$ DHR (one-dimensional DHRs assembled by $\mathrm{In}_{2} \mathrm{O}_{3}$ nanoparticles without the carbon layer, Supplementary Fig. 10), $\operatorname{In}_{2} \mathrm{O}_{3}$ HD (three-dimensional double-shelled hollow dodecahedron assembled by $\mathrm{In}_{2} \mathrm{O}_{3}$ nanoparticles without the carbon layer, Supplementary Figure 11), and commercial $\operatorname{In}_{2} \mathrm{O}_{3}$ in order to investigate the influence of unique structural features of $\mathrm{N}, \mathrm{S}-\mathrm{C} /$ $\mathrm{In}_{2} \mathrm{O}_{3}$ DHR on the light absorption ability. Figure $4 \mathrm{a}$ shows that the $\mathrm{N}, \mathrm{S}-\mathrm{C} / \mathrm{In}_{2} \mathrm{O}_{3}$ DHR possesses the strongest and broadest absorption in a visible-light region under the same conditions, and the optical absorption of other five samples follows the order of N,S-C/ $\mathrm{In}_{2} \mathrm{O}_{3} \mathrm{NP}>\mathrm{N}-\mathrm{C} / \mathrm{In}_{2} \mathrm{O}_{3} \mathrm{NP}>\mathrm{In}_{2} \mathrm{O}_{3} \mathrm{DHR}>\mathrm{In}_{2} \mathrm{O}_{3} \mathrm{HD}>$ commercial $\mathrm{In}_{2} \mathrm{O}_{3}$. This result indicates that N,S-codoped carbon layer and DHR structure play a synergistic role in enhancing the optical absorption ability of $\mathrm{N}, \mathrm{S}-\mathrm{C} / \mathrm{In}_{2} \mathrm{O}_{3}$ DHR.

The separation and migration of electron-hole pairs is the second step of photocatalysis. In order to investigate this step, we measured the electrochemical impedance spectroscopy (EIS), photocurrent density, and linear sweep voltammetry (LSV) of N,S-C/ $\mathrm{In}_{2} \mathrm{O}_{3} \mathrm{DHR}$, $\mathrm{N}, \mathrm{S}-\mathrm{C} / \mathrm{In}_{2} \mathrm{O}_{3} \mathrm{NP}, \mathrm{N}-\mathrm{C} / \mathrm{In}_{2} \mathrm{O}_{3} \mathrm{NP}, \mathrm{In}_{2} \mathrm{O}_{3} \mathrm{DHR}, \mathrm{In}_{2} \mathrm{O}_{3} \mathrm{HD}$ and commercial $\mathrm{In}_{2} \mathrm{O}_{3}$. The LSV curves (Fig. $4 \mathrm{~b}$ ) of these six samples indicate that the $\mathrm{N}, \mathrm{S}-\mathrm{C} / \mathrm{In}_{2} \mathrm{O}_{3}$ DHR has the highest cathodic current density (CCD) for reducing $\mathrm{H}_{2} \mathrm{O}$ to $\mathrm{H}_{2}$. Moreover, the CCD of N,S$\mathrm{C} / \mathrm{In}_{2} \mathrm{O}_{3} \mathrm{NP}$ is higher than that of $\mathrm{N}-\mathrm{C} / \mathrm{In}_{2} \mathrm{O}_{3} \mathrm{NP}$. We then compared the LSV curves of the three samples without the coated carbon layer $\left(\mathrm{In}_{2} \mathrm{O}_{3}\right.$ DHR, $\mathrm{In}_{2} \mathrm{O}_{3} \mathrm{HD}$ and commercial $\left.\mathrm{In}_{2} \mathrm{O}_{3}\right)$, and found that the $\mathrm{In}_{2} \mathrm{O}_{3}$ DHR showed higher CCD than $\mathrm{In}_{2} \mathrm{O}_{3} \mathrm{HD}$ and commercial $\operatorname{In}_{2} \mathrm{O}_{3}$. Thus, it can be concluded that the N,Scodoped carbon layer and one-dimensional hollow rod structure are both beneficial to accelerate the charge transfer. As shown in Fig. 4c, the order of photocurrent density among these six samples is N,S$\mathrm{C} / \mathrm{In}_{2} \mathrm{O}_{3}$ DHR $>\mathrm{N}, \mathrm{S}-\mathrm{C} / \mathrm{In}_{2} \mathrm{O}_{3} \mathrm{NP}>\mathrm{N}-\mathrm{C} / \mathrm{In}_{2} \mathrm{O}_{3} \mathrm{NP}>\mathrm{In}_{2} \mathrm{O}_{3} \mathrm{DHR}>$ $\mathrm{In}_{2} \mathrm{O}_{3} \mathrm{HD}>$ commercial $\mathrm{In}_{2} \mathrm{O}_{3}$, indicating that the $\mathrm{N}, \mathrm{S}-\mathrm{C} / \mathrm{In}_{2} \mathrm{O}_{3}$ DHR also has the highest separation efficiency of photogenerated carriers. Their photoluminescence (PL) emission spectra (Supplementary Fig. 12) were recorded to prove the high-resolution rate of photogenerated carriers. The emission peak at $498 \mathrm{~nm}$ was assigned to the band-band PL phenomenon. The intensity of the peaks shows the order of N,S-C/ $\operatorname{In}_{2} \mathrm{O}_{3}$ DHR $<\mathrm{N}, \mathrm{S}-\mathrm{C} / \mathrm{In}_{2} \mathrm{O}_{3} \mathrm{NP}<\mathrm{N}-\mathrm{C} /$ $\mathrm{In}_{2} \mathrm{O}_{3} \mathrm{NP}<\mathrm{In}_{2} \mathrm{O}_{3} \quad \mathrm{DHR}<\mathrm{In}_{2} \mathrm{O}_{3} \quad \mathrm{HD}<$ commercial $\mathrm{In}_{2} \mathrm{O}_{3}$. The emission intensity of $\mathrm{N}, \mathrm{S}-\mathrm{C} / \mathrm{In}_{2} \mathrm{O}_{3}$ DHR nearly vanish, meaning that the N,S-codoped carbon layer acts as the electron acceptor to effectively prevent the recombination of photogenerated carriers. This result is well consistent with the photocurrent density study. Figure $4 \mathrm{~d}$ shows the electrochemical impedance spectra of these six samples. The $\mathrm{N}, \mathrm{S}-\mathrm{C} / \mathrm{In}_{2} \mathrm{O}_{3}$ DHR presents the smallest semicircular curve in the Nyquist plot, indicating its lowest charge-transfer 

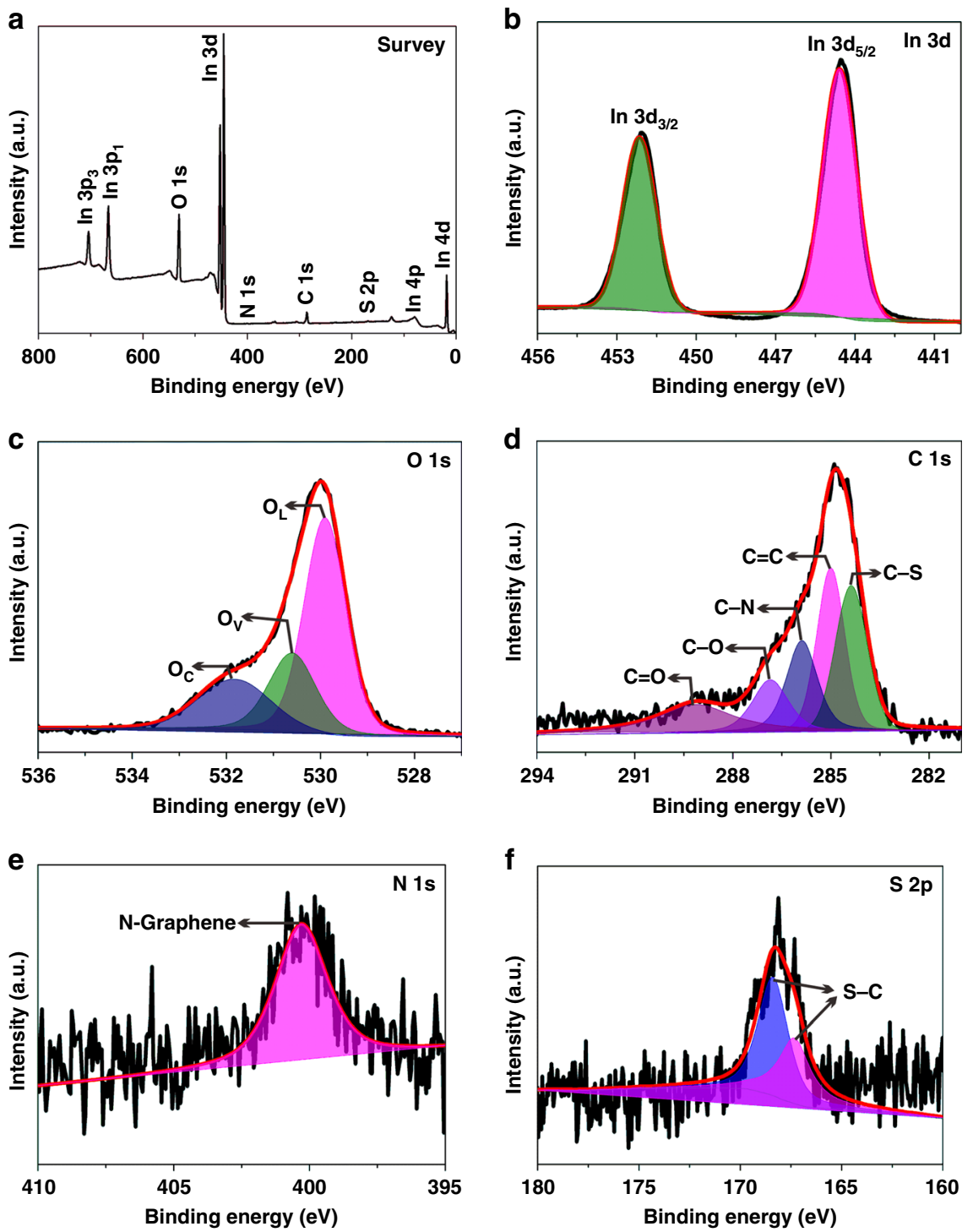

Fig. 3 XPS spectra of $\mathrm{N}, \mathrm{S}-\mathrm{C} / \mathrm{In}_{2} \mathrm{O}_{3}$ DHR. a Survey spectrum, and high-resolution spectra of $\mathbf{b} \ln 3 \mathrm{~d}$, $\mathbf{c} \mathrm{O} 1 \mathrm{~s}$, d C 1s, e $\mathrm{N} 1 \mathrm{~s}$, and $\mathbf{f} \mathrm{S} 2 \mathrm{p}$. Source data are provided as a Source Data file

resistance, which is consistent with its more effective separation of photogenerated electrons and holes ${ }^{47}$. Therefore, N,S-codoped C layer evenly coated on $\mathrm{In}_{2} \mathrm{O}_{3}$ provides the electron storage and transfer channel to improve the separation efficiency of photogenerated carriers.

Photocatalytic activity of the photocatalysts. Photocatalytic activity of the as-prepared N,S-C/ $\operatorname{In}_{2} \mathrm{O}_{3}$ DHR was evaluated by blue light LED induced oxidative hydroxylation of arylboronic acids (OHAA) to phenols. Phenols are very important intermediates for many polymers, natural products and pharmaceutical molecules ${ }^{48-52}$. The photocatalytic reactions were carried out using $N, N$-diisopropylethylamine (DIEA) as the sacrificing agent (Fig. 5a). The details for determining the optimized conditions for this photocatalytic reaction are shown in Supplementary Table 1. When compared with $\mathrm{N}, \mathrm{S}-\mathrm{C} / \mathrm{In}_{2} \mathrm{O}_{3} \mathrm{NP}, \mathrm{N}-\mathrm{C} / \mathrm{In}_{2} \mathrm{O}_{3} \mathrm{NP}, \mathrm{In}_{2} \mathrm{O}_{3}$ $\mathrm{DHR}, \mathrm{In}_{2} \mathrm{O}_{3} \mathrm{HD}$ and commercial $\mathrm{In}_{2} \mathrm{O}_{3}$ (Fig. 5b and Supplementary Fig. 13), N,S-C/ $/ \mathrm{In}_{2} \mathrm{O}_{3}$ DHR exhibits the highest catalytic activity with the production yield reaching about $99 \%$ after $12 \mathrm{~h}$ (determined by ${ }^{1} \mathrm{H}$ NMR spectra, Supplementary Fig. 14). Compared to N-C/ $\operatorname{In}_{2} \mathrm{O}_{3} \mathrm{HD}$ (the $\mathrm{In}_{2} \mathrm{O}_{3}$ dodecahedron coated by $\mathrm{N}$-doped C layer $)^{43}$, the catalytic time of N,S-C/ $\operatorname{In}_{2} \mathrm{O}_{3}$ DHR for achieving $99 \%$ production yield is reduced to half, indicating that the N,S-codoping plays an importantly positive role in improving the activity of carbon-coated photocatalysts. On the other hand, the photocatalyst is relatively less active under green and yellow light irradiation for $12 \mathrm{~h}$, with the yields of 44 and 15\%, respectively (Supplementary Fig. 15). The photocatalytic activity of other five samples follows the trend of $\mathrm{N}, \mathrm{S}-\mathrm{C} / \mathrm{In}_{2} \mathrm{O}_{3} \mathrm{NP}>\mathrm{N}-\mathrm{C} /$ $\mathrm{In}_{2} \mathrm{O}_{3} \mathrm{NP}>\mathrm{In}_{2} \mathrm{O}_{3}$ DHR $>\mathrm{In}_{2} \mathrm{O}_{3} \mathrm{HD}>$ commercial $\mathrm{In}_{2} \mathrm{O}_{3}$, which is consistent with the analytic results shown in Fig. 4. Therefore, effective photocatalytic activity of $\mathrm{N}, \mathrm{S}-\mathrm{C} / \mathrm{In}_{2} \mathrm{O}_{3}$ DHR should be assigned to the efficient separation of photogenerated carriers induced by uniform coating of the N,S-codoped C layer and enhanced optical absorption provided by the N,S-codoped C layer and DHR structure.

In order to access the recycling stability of $\mathrm{N}, \mathrm{S}-\mathrm{C} / \mathrm{In}_{2} \mathrm{O}_{3} \mathrm{DHR}$, the same photocatalytic OHAA was carried out for five cycles with an interval of $12 \mathrm{~h}$. The $\mathrm{N}, \mathrm{S}-\mathrm{C} / \mathrm{In}_{2} \mathrm{O}_{3}$ DHR exhibits high recycling stability and stable photocatalytic efficiency (Fig. 5c). The shape and structure of the N,S-C/ $/ \mathrm{In}_{2} \mathrm{O}_{3}$ DHR did not show obvious changes after photocatalytic cycle experiments (Supplementary Fig. 16). After keeping the solutions for $12 \mathrm{~h}, \mathrm{~N}, \mathrm{~S}-\mathrm{C} /$ $\mathrm{In}_{2} \mathrm{O}_{3}$ DHR precipitated to the bottom of solution, while N,S-C/ 
a
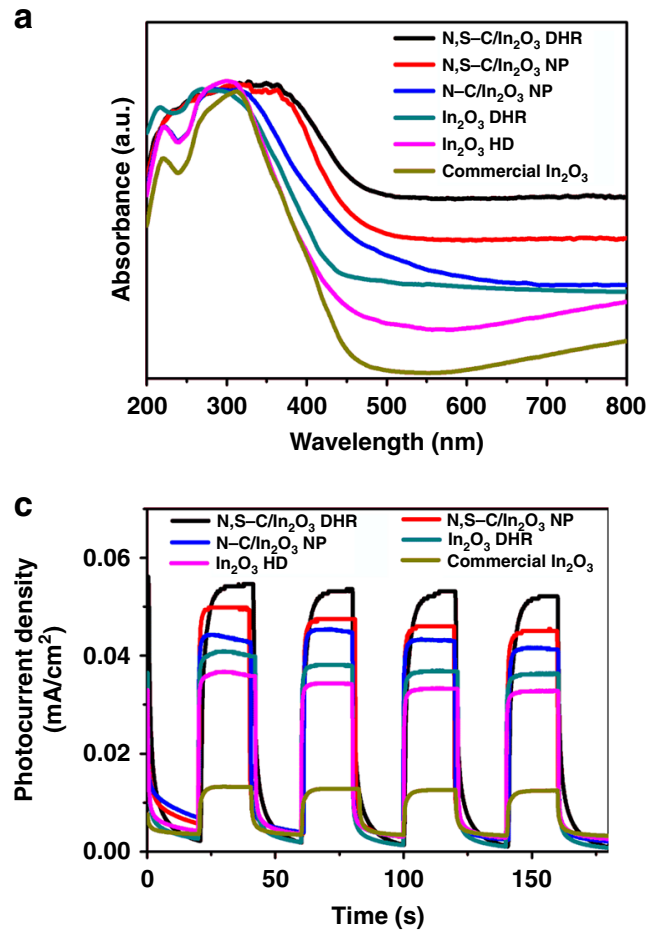

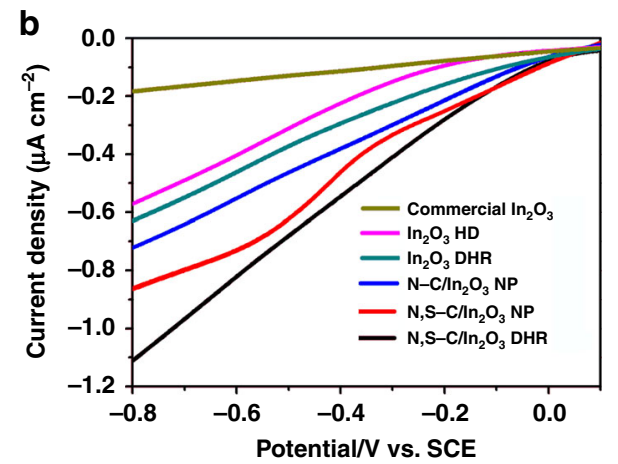

d

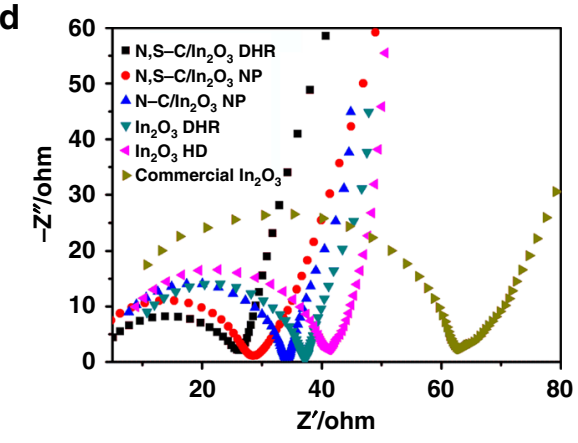

Fig. 4 Optical absorption and photoelectric characterizations. a UV-vis absorption spectra, b LSV curves, c Photocurrent density measured at $0.2 \mathrm{~V}$ versus $\mathrm{Hg} / \mathrm{Hg}_{2} \mathrm{Cl}_{2}$ under non-illuminated (i.e., in the dark) and illuminated conditions, and d EIS Nyquist plots for N,S-codoped $\ln _{2} \mathrm{O}_{3} \mathrm{DHR}, \mathrm{N}, \mathrm{S}-\mathrm{C} / \mathrm{In} \mathrm{n}_{2} \mathrm{O}_{3} \mathrm{NP}, \mathrm{N}-\mathrm{C} /$ $\mathrm{In}_{2} \mathrm{O}_{3} \mathrm{NP}, \mathrm{In}_{2} \mathrm{O}_{3} \mathrm{DHR}, \mathrm{In}_{2} \mathrm{O}_{3} \mathrm{HD}$, and commercial $\ln _{2} \mathrm{O}_{3}$. Source data are provided as a Source Data file
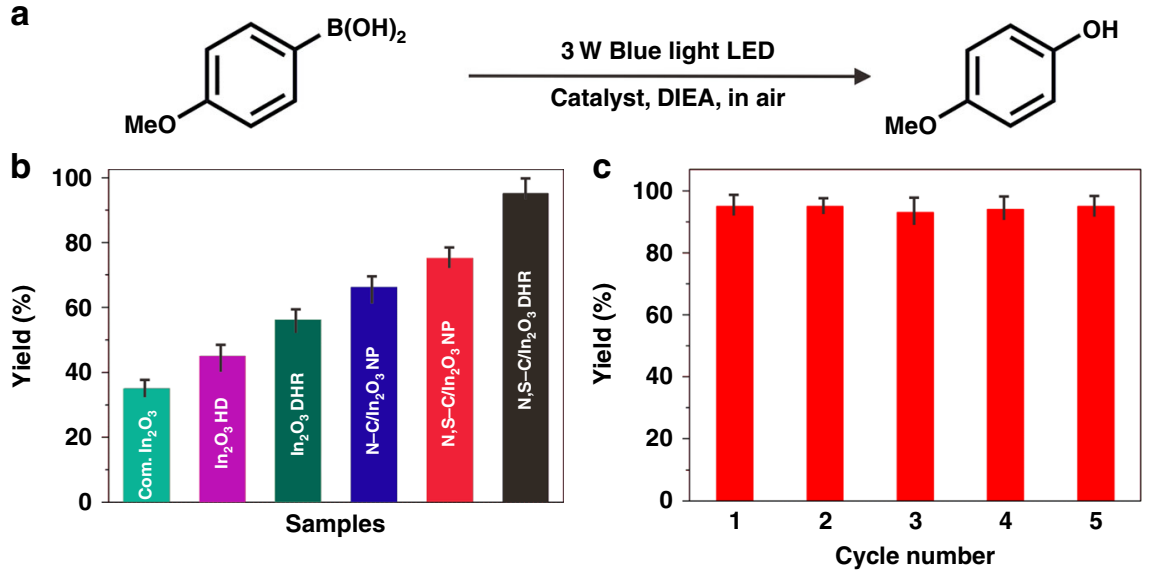

d

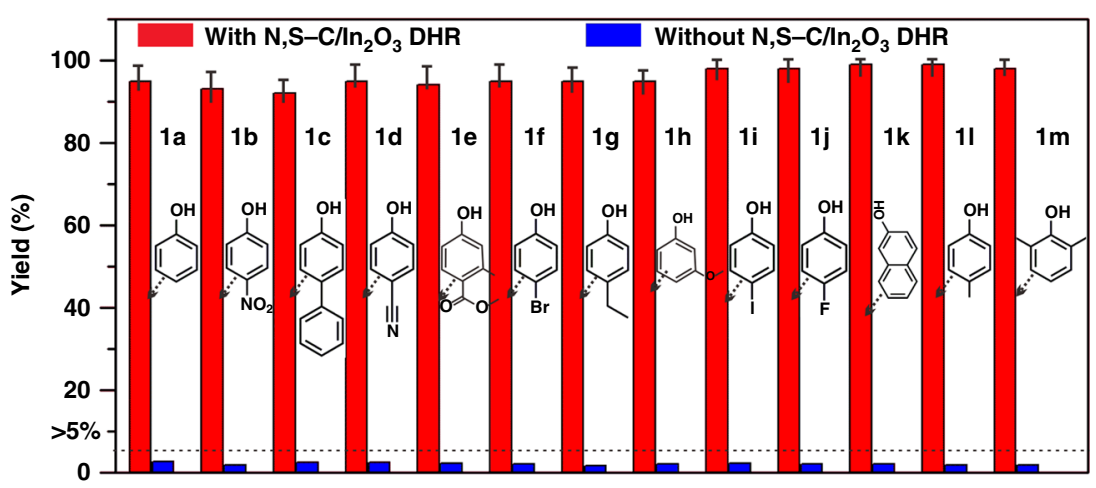

Fig. 5 Photocatalytic oxidative hydroxylation. a Photocatalytic reaction for OHAA. b Reaction yields from OHAA using N,S-C/In $\mathrm{O}_{3} D H R, N, S-C / I n_{2} \mathrm{O}_{3} N P$, $\mathrm{N}-\mathrm{C} / \mathrm{In}_{2} \mathrm{O}_{3} \mathrm{NP}, \mathrm{In}_{2} \mathrm{O}_{3} \mathrm{DHR}, \ln _{2} \mathrm{O}_{3} \mathrm{HD}$, and commercial (com.) $\ln _{2} \mathrm{O}_{3}$ as catalysts for $12 \mathrm{~h}$. c Recycling tests for OHAA using N,S-C/In $\mathrm{O}_{3}$ DHR as a catalyst under blue LED irradiation. d Reaction yields of various phenols obtained from oxidative hydroxylation of different arylboronic acids with and without $\mathrm{N}, \mathrm{S}-$ $\mathrm{C} / \mathrm{In}_{2} \mathrm{O}_{3} \mathrm{DHR}$ as a photocatalyst. Source data are provided as a Source Data file 

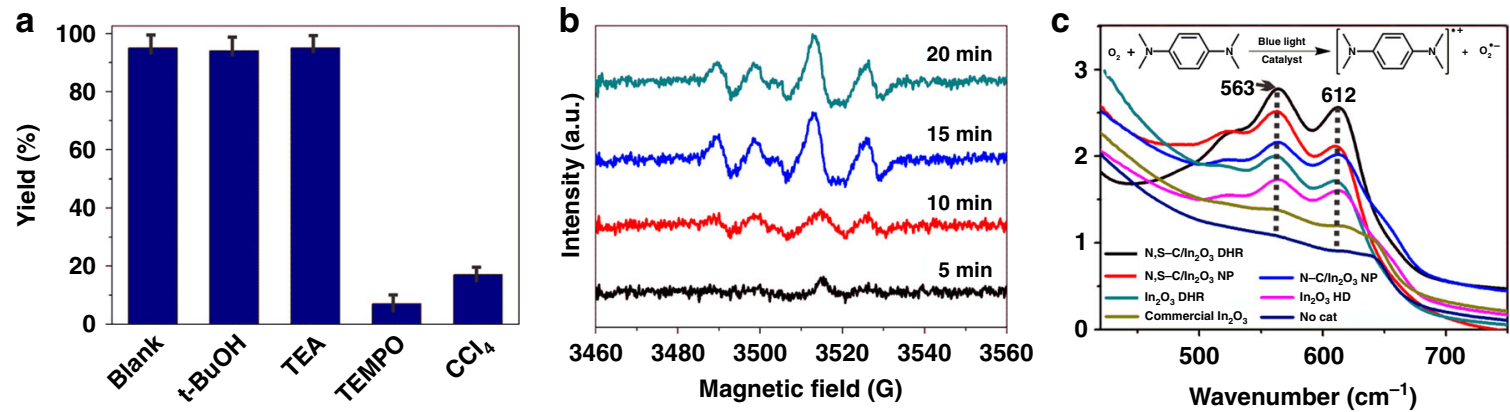

Fig. 6 Photocatalytic mechanism studies. a Control experiments for OHAA over $\mathrm{N}, \mathrm{S}-\mathrm{C} / \mathrm{In}_{2} \mathrm{O}_{3}$ DHR under blue LED irradiation in the presence of different scavengers: no scavenger (blank), t-BuOH, TEA, TEMPO, and $\mathrm{CCl}_{4}$. $\mathbf{b}$ EPR spectra of a reaction solution in the present of DMPO under blue LED irradiation for different times. c UV-vis absorption spectra for cationic radicals of TMPD treated by N,S-C/In $\mathrm{O}_{3} \mathrm{DHR}, \mathrm{N}, \mathrm{S}-\mathrm{C} / \mathrm{In}_{2} \mathrm{O}_{3} \mathrm{NP}, \mathrm{N}-\mathrm{C} / \mathrm{In} \mathrm{n}_{2} \mathrm{O}_{3} \mathrm{NP}, \mathrm{In} \mathrm{O}_{2} \mathrm{O}$ DHR, $\mathrm{In}_{2} \mathrm{O}_{3} \mathrm{HD}$, and commercial $\mathrm{In}_{2} \mathrm{O}_{3}$ under blue LED light irradiation. Source data are provided as a Source Data file

$\mathrm{In}_{2} \mathrm{O}_{3} \mathrm{NP}$ still suspended in the solution (Supplementary Fig. 17). Therefore, the $\mathrm{N}, \mathrm{S}-\mathrm{C} / \mathrm{In}_{2} \mathrm{O}_{3}$ DHR can be recovered from the solution through simple centrifugation. We also measured the dispersity of $\mathrm{N}, \mathrm{S}-\mathrm{C} / \mathrm{In}_{2} \mathrm{O}_{3}$ DHR in the reaction solution. N,S-C/ $\mathrm{In}_{2} \mathrm{O}_{3}$ DHR can be well dispersed in the solution under continuous stirring (Supplementary Fig. 18). The catalytic activity of the N,S-C/ $/ \mathrm{In}_{2} \mathrm{O}_{3}$ DHR for OHAA with various substrates was also investigated under the same catalytic experimental conditions (Fig. 5d). The corresponding reaction yields of the products are about $90-95 \%$, indicating that the efficient photocatalytic activity of N,S-C/ $\operatorname{In}_{2} \mathrm{O}_{3}$ DHR is not specific to only one reaction, but highly suitable for a series of OHAA.

Photocatalytic mechanism for OHAA. In order to understand the photocatalytic mechanism using $\mathrm{N}, \mathrm{S}-\mathrm{C} / \mathrm{In}_{2} \mathrm{O}_{3}$ DHR as the photocatalyst, the energy band position of $\mathrm{In}_{2} \mathrm{O}_{3}$ was first calculated. As show in Supplementary Fig. 19, the absorption edge presents at $443 \mathrm{~nm}$ in visible-light region. The bandgap of the $\mathrm{In}_{2} \mathrm{O}_{3}$ DHR was estimated to $2.8 \mathrm{eV}$, matching well with the reported value ${ }^{53}$. Thus, the $\mathrm{In}_{2} \mathrm{O}_{3}$ DHR works well under blue LED light irradiation $(E=2.76 \pm 4 \mathrm{eV})^{54}$. The VB potential of $\mathrm{In}_{2} \mathrm{O}_{3}$ can be calculated by Mulliken electronegativity theory:

$$
E_{\mathrm{VB}}=X-E^{e}+0.5 E_{\mathrm{g}}
$$

where $E_{\mathrm{VB}}$ is corresponding $\mathrm{VB}$ potential, $X$ is the absolute electro-negativity of corresponding semiconductor, $E^{e}$ is the energy of free electrons in the hydrogen scale (about $4.5 \mathrm{eV}$ ), and $E_{\mathrm{g}}$ is the bandgap energy of corresponding semiconductor. The $X$ value for $\mathrm{In}_{2} \mathrm{O}_{3}$ is $5.19 \mathrm{eV}$, and thus the $E_{\mathrm{VB}}$ value of $\mathrm{In}_{2} \mathrm{O}_{3}$ is calculated to be $2.09 \mathrm{eV}$. The $E_{\mathrm{VB}}$ value was also confirmed by the VB XPS (Supplementary Fig. 20). The CB potential $\left(E_{\mathrm{CB}}\right)$ can be obtained by:

$$
E_{\mathrm{CB}}=E_{\mathrm{VB}}-E_{\mathrm{g}}
$$

In order to reflect the effect of $\mathrm{pH}$, the following equation was used to calculate the $E_{\mathrm{VB}}$ and $E_{\mathrm{CB}}$ potentials of the photocatalyst:

$$
E=E^{0}-0.05915 \times \mathrm{pH}
$$

Thus, the $E_{\mathrm{VB}}$ and $E_{\mathrm{CB}}$ values of $\operatorname{In}_{2} \mathrm{O}_{3}$ at $\mathrm{pH}=7$ were estimated to be 1.68 and $-1.12 \mathrm{~V}$ vs normal hydrogen electrode (NHE), respectively.

A series of comparative experiments were performed by adding various radical scavengers into the reaction system to investigate the major reactive species in the photocatalytic OHAA. Tertiary butanol $(\mathrm{t}-\mathrm{BuOH})$ was adopted to extinguish hydroxyl radical $(\cdot \mathrm{OH})$, triethylamine (TEA) was introduced to quench photogenerated hole $\left(\mathrm{h}^{+}\right)$, (2,2,6,6-tetramethylpiperidin-1-yl)oxidanyl
(TEMPO) was employed to scavenge superoxide anion radical $\left(\cdot \mathrm{O}_{2}^{-}\right)$, and $\mathrm{CCl}_{4}$ was used for trapping photogenerated electron $\left(\mathrm{e}^{-}\right)^{55-57}$. As illustrated in Fig. 6a, before and after adding TEA and $\mathrm{t}-\mathrm{BuOH}$, the yield of corresponding phenol remains almost unchanged (Supplementary Figures 21-23). When TEMPO is added to quench $\cdot \mathrm{O}_{2}{ }^{-}$, the yield of phenol is significantly suppressed (Supplementary Figure 24). Noticeable inhibition can be also observed when $\mathrm{CCl}_{4}$ is added to trap $\mathrm{e}^{-}$(Supplementary Figure 25). These results reveal that the $\mathrm{e}^{-}$and $\cdot \mathrm{O}_{2}^{-}$play the key roles in OHAA using $\mathrm{N}, \mathrm{S}-\mathrm{C} / \mathrm{In}_{2} \mathrm{O}_{3}$ DHR as the photocatalyst. Electron paramagnetic resonance (EPR) was used to prove the existence of $\cdot \mathrm{O}_{2}{ }^{-}$, which was captured by adding 5,5-dimethyl-1pyrroline-N-oxide (DMPO). Obvious characteristic signals of . $\mathrm{O}_{2}{ }^{-}$can be detected when DMPO is used as the radical scavenger, and the intensity of the signals gradually increases upon the illumination time (Fig. 6b). The results indicate that . $\mathrm{O}_{2}{ }^{-}$is the primary active intermediate species in this photocatalytic process.

The superoxide anion radical $\cdot \mathrm{O}_{2}{ }^{-}$can only be produced by reacting dissolved $\mathrm{O}_{2}$ with photogenerated electrons under the $\mathrm{CB}$ potential of $\mathrm{O}_{2} / \cdot \mathrm{O}_{2}{ }^{-}(-0.33 \mathrm{~V}$ vs $\mathrm{NHE})$. In this system, the $\mathrm{CB}$ potential $(-1.12 \mathrm{~V}$ vs $\mathrm{NHE})$ of $\mathrm{In}_{2} \mathrm{O}_{3}$ is high enough to form . $\mathrm{O}_{2}{ }^{-}$based on the thermodynamic viewpoint. The generation of $\cdot \mathrm{O}_{2}-$ in the $\mathrm{N}, \mathrm{S}-\mathrm{C} / \mathrm{In}_{2} \mathrm{O}_{3}$ DHR system was further verified by using $\mathrm{N}, \mathrm{N}, \mathrm{N}^{\prime}, \mathrm{N}^{\prime}$-tetramethyl-phenylenediamine (TMPD), because the photoactive systems can regulate the electrons transfer from TMPD molecule to $\mathrm{O}_{2}$, resulting in the production of $\cdot \mathrm{O}_{2}{ }^{-}$and blue-colored product with obvious absorption peaks at $612 \mathrm{~nm}$ and $563 \mathrm{~nm}^{58}$. All of the six samples $\left(\mathrm{N}, \mathrm{S}-\mathrm{C} / \mathrm{In}_{2} \mathrm{O}_{3}\right.$ DHR, N,S-C/In ${ }_{2} \mathrm{O}_{3} \mathrm{NP}, \mathrm{N}-\mathrm{C} / \mathrm{In}_{2} \mathrm{O}_{3} \mathrm{NP}, \mathrm{In}_{2} \mathrm{O}_{3} \mathrm{DHR}, \mathrm{In}_{2} \mathrm{O}_{3} \mathrm{HD}$ and commercial $\mathrm{In}_{2} \mathrm{O}_{3}$ ) produce characteristic absorption peaks after reacting with TMPD (Fig. 6c), indicating that $\operatorname{In}_{2} \mathrm{O}_{3}$ has the ability to generate $\cdot \mathrm{O}_{2}{ }^{-}$. The characteristic absorption peak intensity of these six samples follows the order of $\mathrm{N}, \mathrm{S}-\mathrm{C} / \mathrm{In}_{2} \mathrm{O}_{3}$ $\mathrm{DHR}>\mathrm{N}, \mathrm{S}-\mathrm{C} / \mathrm{In}_{2} \mathrm{O}_{3} \mathrm{NP}>\mathrm{N}-\mathrm{C} / \mathrm{In}_{2} \mathrm{O}_{3} \mathrm{NP}>\mathrm{In}_{2} \mathrm{O}_{3} \quad \mathrm{DHR}>\mathrm{In}_{2} \mathrm{O}_{3}$ $\mathrm{HD}>$ commercial $\mathrm{In}_{2} \mathrm{O}_{3}$, which is consistent with the trend of the separation and migration ability of photogenerated carriers. The high-resolution $\mathrm{O}$ 1s spectra of these six $\operatorname{In}_{2} \mathrm{O}_{3}$ samples were measured to investigate the surface structures of photocatalysts (Supplementary Fig. 26 and Supplementary Table 2). Relative proportion of the oxygen vacancy $\left(\mathrm{O}_{\mathrm{V}}\right)$ component in these samples is in the order of N,S-C/ $\mathrm{In}_{2} \mathrm{O}_{3} \mathrm{DHR}>\mathrm{N}, \mathrm{S}-\mathrm{C} / \mathrm{In}_{2} \mathrm{O}_{3} \mathrm{NP}>$ $\mathrm{N}-\mathrm{C} / \mathrm{In}_{2} \mathrm{O}_{3} \mathrm{NP}>\mathrm{In}_{2} \mathrm{O}_{3}$ DHR $>\mathrm{In}_{2} \mathrm{O}_{3} \mathrm{HD}>$ commercial $\mathrm{In}_{2} \mathrm{O}_{3}$, indicating that the $\mathrm{O}_{\mathrm{V}}$ provides the site for activating $\mathrm{O}_{2}$ to $\cdot \mathrm{O}_{2}{ }^{-}$. In the $\mathrm{N}, \mathrm{S}-\mathrm{C} / \mathrm{In}_{2} \mathrm{O}_{3} \mathrm{DHR}$ system, $\cdot \mathrm{O}_{2}{ }^{-}$is the main reactive species for photocatalytic OHAA, and $\mathrm{e}^{-}$is responsible for reducing the oxygen molecule to produce $\cdot \mathrm{O}_{2}{ }^{-}$. 


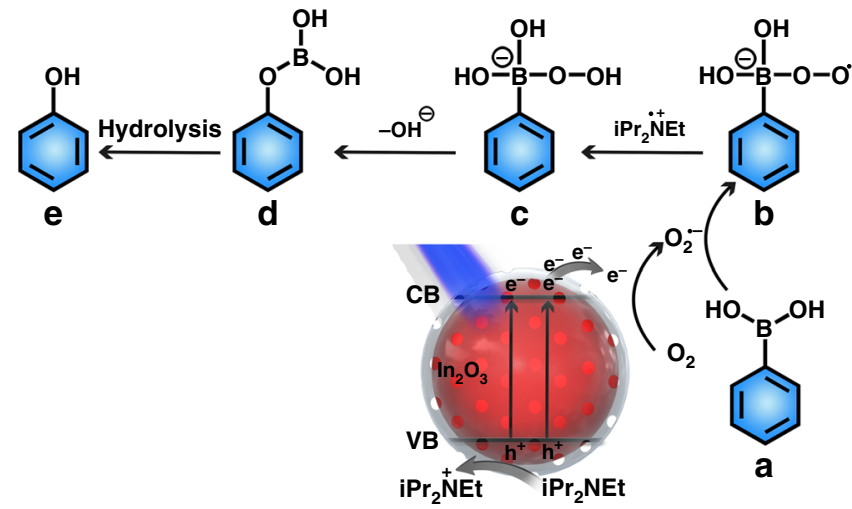

Fig. 7 Schematic illustration exhibiting the proposed reaction mechanism (a-e) for OHAA using N,S-C/ $\ln _{2} \mathrm{O}_{3} \mathrm{DHR}$ as the photocatalyst

Based on above studies, a possible photocatalytic mechanism of OHAA over N,S-C/ $\mathrm{In}_{2} \mathrm{O}_{3}$ DHR was proposed (Fig. 7). Firstly, the photogenerated carriers are excited in $\mathrm{N}, \mathrm{S}-\mathrm{C} / \mathrm{In}_{2} \mathrm{O}_{3}$ DHR under blue LED irradiation. Then, the photogenerated electrons are transferred to the N,S-codoped carbon layer, and the photogenerated holes still stay on the $\operatorname{In}_{2} \mathrm{O}_{3}$ nanoparticles. Secondly, the adsorbed $\mathrm{O}_{2}$ molecule is reduced by separated electrons, resulting in the formations of $\cdot \mathrm{O}_{2}{ }^{-}$. The DIEA molecule $\left(\mathrm{iPr}_{2} \mathrm{Net}\right)$ can capture the separated holes to form $\mathrm{iPr}_{2} \mathrm{~N}^{+}$Et. Thirdly, the obtained $\cdot \mathrm{O}_{2}{ }^{-}$would react with arylboronic acid molecule (a) to generate intermediate (b). The intermediate (b) then abstracts a hydrogen atom from $\mathrm{iPr}_{2} \mathrm{~N}^{+} \mathrm{Et}$ to form intermediate (c), which is further rearranged with the loss of a $-\mathrm{OH}^{-}$ion to form (d). The intermediate (d) is subsequently hydrolyzed to afford the final phenol product (e).

Microcosmic mechanism of photogenerated carrier separation and transfer on N,S-codoped $\operatorname{In}_{2} \mathrm{O}_{3}$ was further investigated by calculating the projected density of states (PDOS) from $\operatorname{In}_{2} \mathrm{O}_{3}$ (001) face/N,S-codoped graphite (001) face, $\operatorname{In}_{2} \mathrm{O}_{3}(110)$ face/N,Scodoped graphite (001) face, and $\operatorname{In}_{2} \mathrm{O}_{3}$ (111) face/N,S-codoped graphite (001) face, respectively. As shown in Fig. 8, the hybrid states of C $2 p$ orbital, S $3 p$ orbital, and N 2p orbital cross over the bandgap of $\operatorname{In}_{2} \mathrm{O}_{3}$ in the three $\operatorname{In}_{2} \mathrm{O}_{3} / \mathrm{N}$,S-codoped graphite interfaces, meaning that the electrons from $\mathrm{O} 2 \mathrm{p}$ state of $\operatorname{In}_{2} \mathrm{O}_{3}$ would be transferred to these hybrid states of graphite. Moreover, the hybridization of N $2 p, S 3 p$, and C $2 p$ increases the strength of interstitial states to further improve the separation and transfer rate of photogenerated carriers. Thus, electrons are mainly excited from $\mathrm{O} 2 \mathrm{p}$ state of $\operatorname{In}_{2} \mathrm{O}_{3}$ to hybrid states of graphite $(\mathrm{N} 2 \mathrm{p}, \mathrm{S} 3 \mathrm{p}$, and $\mathrm{C} 2 \mathrm{p}$ orbitals) through the interface, leaving the photogenerated holes on $\mathrm{O} 2 \mathrm{p}$ state of $\mathrm{In}_{2} \mathrm{O}_{3}$.

\section{Discussion}

In conclusion, the double-shelled hollow rods $\left(\mathrm{N}, \mathrm{S}-\mathrm{C} / \mathrm{In}_{2} \mathrm{O}_{3}\right.$ DHR) assembled by N,S-codoped $\mathrm{C}$ coated $\mathrm{In}_{2} \mathrm{O}_{3}$ ultrafine nanoparticles have been synthesized by thermolysis of In-based frameworks. The obtained N,S-C/ $\operatorname{In}_{2} \mathrm{O}_{3}$ DHR possesses effective catalytic activity for photocatalytic OHAA with high stability and easy recovery at the same time. The excellent performance of N,S$\mathrm{C} / \mathrm{In}_{2} \mathrm{O}_{3}$ DHR in the photocatalysis is due to the following four structural characteristics. Firstly, the hollow rods not only provide a local microenvironment for OHAA, but also enhance the light absorption by increasing the optical reflection in the hollow interior to generate more electrons and holes. Secondly, the double shells of N,S-C/ $\mathrm{In}_{2} \mathrm{O}_{3}$ DHR have lots of reactive sites, which improve the photocatalytic activity. Thirdly, the mesoporous structure of the shells improves the accessibility of N,S-C/ $\mathrm{In}_{2} \mathrm{O}_{3}$ DHR, which is beneficial for the diffusion of reactants and

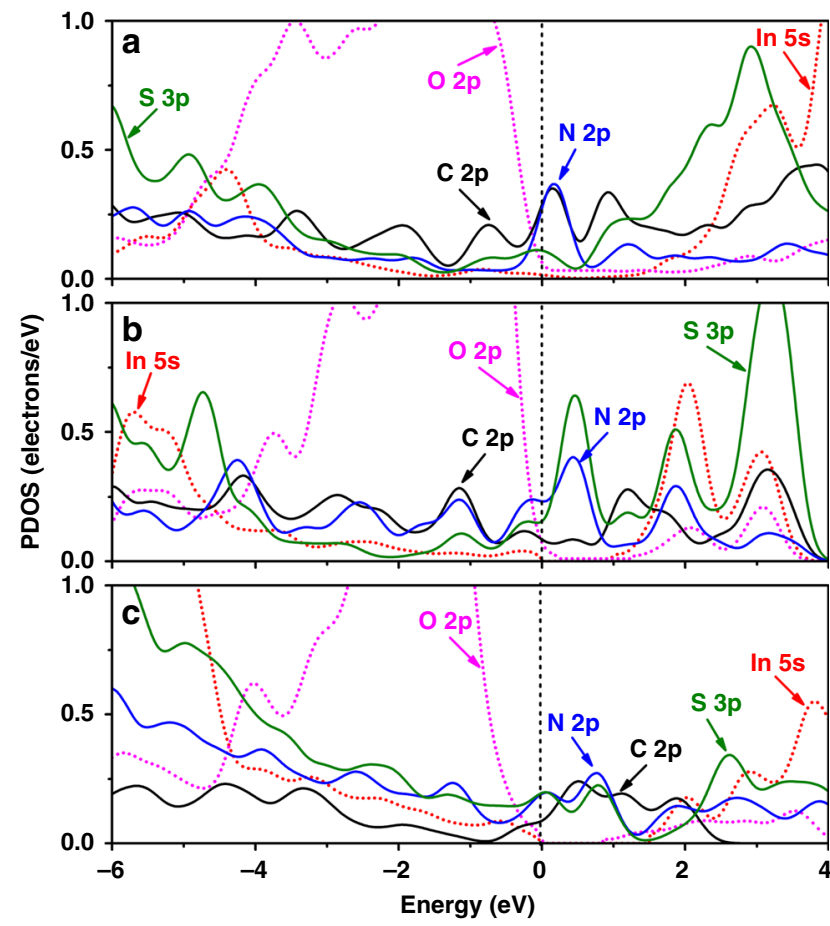

Fig. 8 Density functional theory calculations. PDOS for $\mathbf{a} \ln _{2} \mathrm{O}_{3}(100)$ face/ $\mathrm{N}, \mathrm{S}$-codoped graphite (001) face, $\mathbf{b} \ln _{2} \mathrm{O}_{3}$ (110) face/N, S-codoped graphite (001) face, and $\mathbf{c} \ln _{2} \mathrm{O}_{3}$ (111) face/N, S-codoped graphite (001) face

products. Fourthly, the regular morphology and large size (6-7 $\mu \mathrm{m}$ in length) of $\mathrm{N}, \mathrm{S}-\mathrm{C} / \mathrm{In}_{2} \mathrm{O}_{3}$ DHR significantly improve the recyclability and reusability. The photocatalytic mechanism of OHAA over $\mathrm{N}, \mathrm{S}-\mathrm{C} / \mathrm{In}_{2} \mathrm{O}_{3}$ DHR has been proposed, confirming that $\cdot \mathrm{O}_{2}{ }^{-}$is the primary reactive species in this catalytic reaction. In addition, the microcosmic separation and transfer pathways via the interface of $\operatorname{In}_{2} \mathrm{O}_{3} / \mathrm{N}$,S-codoped graphite have been clarified by PDOS theoretical calculations, i.e., photogenerated electrons are mainly excited from $\mathrm{O} 2 \mathrm{p}$ state of $\operatorname{In}_{2} \mathrm{O}_{3}$ and transferred to hybrid states of the graphite consisting of $S 3 p, N 2 p$, and $C 2 p$ orbitals, leaving photogenerated holes on $\mathrm{O} 2 \mathrm{p}$ state of $\operatorname{In}_{2} \mathrm{O}_{3}$. Thus, this work presents useful information on the rational exploration of $\operatorname{In}_{2} \mathrm{O}_{3}$-based hybrid materials for achieving highly efficient photocatalysts.

\section{Methods}

Synthesis of N,S-codoped MIL-68-In. Indium(III) nitrate hydrate $(0.21 \mathrm{mmol}$, $0.08 \mathrm{~g}), 1,4$-benzenedicarboxylic acid $(0.18 \mathrm{mmol}, 0.03 \mathrm{~g})$ and BIT $(0.13 \mathrm{mmol}, 0.02$ g) were separately added into $\mathrm{N}, \mathrm{N}$-dimethylformamide $(10 \mathrm{~mL})$. After ultrasonication for $10 \mathrm{~min}$, the above solution was directly transferred to a Teflon-lined steel autoclave $(50 \mathrm{~mL})$ and put in oven at $100^{\circ} \mathrm{C}$ under static conditions for $4 \mathrm{~h}$. When the reaction completed, the sample was obtained by centrifugation, washed with ethanol for several times, and finally dried at $60^{\circ} \mathrm{C}$ for $24 \mathrm{~h}$.

Synthesis of $\mathbf{N}, \mathbf{S}-\mathbf{C} / \mathbf{I n}_{\mathbf{2}} \mathrm{O}_{\mathbf{3}}$ DHR. N,S-C/ $/ \mathrm{In}_{2} \mathrm{O}_{3}$ DHR was obtained via the pyrolysis of the N,S-codoped MIL-68-In precursor in a vacuum atmosphere at $550^{\circ} \mathrm{C}$ with the heating rate of $5^{\circ} \mathrm{C} \mathrm{min}^{-1}$ for $45 \mathrm{~min}$.

Synthesis of $\ln _{\mathbf{2}} \mathbf{O}_{\mathbf{3}}$ DHR. $\operatorname{In}_{2} \mathrm{O}_{3}$ DHR was synthesized via the pyrolysis of the obtained $\mathrm{N}, \mathrm{S}-\mathrm{C} / \mathrm{In}_{2} \mathrm{O}_{3}$ DHR in $\mathrm{O}_{2}$ at $550^{\circ} \mathrm{C}$ with the heating rate of $5^{\circ} \mathrm{C} \mathrm{min}^{-1}$ for $45 \mathrm{~min}$.

Synthesis of $\mathbf{N}, \mathbf{S}-\mathbf{C} / \mathbf{I n}_{\mathbf{2}} \mathbf{O}_{\mathbf{3}} \mathbf{N P}$. Indium(III) nitrate hydrate $(0.21 \mathrm{mmol}, 0.08 \mathrm{~g})$, benzimidazole $(0.25 \mathrm{mmol}, 0.03 \mathrm{~g}), 1,4$-benzenedicarboxylic acid $(0.18 \mathrm{mmol}$, $0.03 \mathrm{~g})$ and BIT $(0.13 \mathrm{mmol}, 0.02 \mathrm{~g})$ were dissolved in methanol $(10 \mathrm{~mL})$. After ultrasonication for about $10 \mathrm{~min}$, the solution was directly poured into a Teflonlined steel autoclave $(50 \mathrm{~mL})$, and put in an oven at $100^{\circ} \mathrm{C}$ under static conditions for $240 \mathrm{~min}$. When the reaction finished, the product was obtained through the centrifugation, which was washed several times with ethanol and finally dried at 
$60{ }^{\circ} \mathrm{C}$ for $24 \mathrm{~h}$. N,S-C/ $/ \mathrm{In}_{2} \mathrm{O}_{3} \mathrm{NP}$ was obtained by the pyrolysis of the product in a vacuum environment at $450^{\circ} \mathrm{C}$ with the heating rate of $2{ }^{\circ} \mathrm{C} \mathrm{min}{ }^{-1}$ for $1 \mathrm{~h}$.

Synthesis of $\mathbf{N}-\mathbf{C} / \mathbf{I n}_{\mathbf{2}} \mathbf{O}_{\mathbf{3}} \mathbf{N P}$. Indium(III) nitrate hydrate $(0.21 \mathrm{mmol}, 0.08 \mathrm{~g})$, benzimidazole $(0.254 \mathrm{mmol}, 0.03 \mathrm{~g})$ and 1,4-benzenedicarboxylic acid $(0.18 \mathrm{mmol}$, $0.03 \mathrm{~g}$ ) were separately added into methanol $(10 \mathrm{~mL})$. After ultrasonication for about $10 \mathrm{~min}$, the solution was directly poured into a Teflon-lined steel autoclave $(50 \mathrm{~mL})$, and put in the oven at $100^{\circ} \mathrm{C}$ under static conditions for $240 \mathrm{~min}$. When the reaction finished, the product was obtained by centrifugation, washed with ethanol for several times, and finally dried at $60^{\circ} \mathrm{C}$ for $24 \mathrm{~h} . \mathrm{N}-\mathrm{C} / \mathrm{In}_{2} \mathrm{O}_{3} \mathrm{NP}$ was obtained by the pyrolysis of the product in a vacuum environment at $450{ }^{\circ} \mathrm{C}$ with the temperature increasing speed of $2^{\circ} \mathrm{C} \min ^{-1}$ for $1 \mathrm{~h}$.

Synthesis of $\ln _{2} \mathbf{O}_{\mathbf{3}}$ HD. Indium(III) nitrate hydrate $(0.040 \mathrm{mmol}, 0.015 \mathrm{~g})$, benzimidazole $(0.846 \mathrm{mmol}, 0.1 \mathrm{~g})$ and 4,5 -imidazoledicarboxylic acid $(0.135 \mathrm{mmol}$, $0.021 \mathrm{~g})$ were separately dissolved in $\mathrm{N}, \mathrm{N}$-dimethylformamide $(6 \mathrm{~mL})$. After ultrasonication for about $10 \mathrm{~min}$, the solution was directly transferred to a round bottom flask $(50 \mathrm{~mL})$ heated at $100{ }^{\circ} \mathrm{C}$ for $4 \mathrm{~h}$. When the reaction finished, the sample was obtained by centrifugation, washed with ethanol for several times, and then dried at $60^{\circ} \mathrm{C}$ for $24 \mathrm{~h}$. The pyrolysis was performed on the sample in an argon environment at $500^{\circ} \mathrm{C}$ with the heating rate about $2{ }^{\circ} \mathrm{C} \mathrm{min}-1$ for $1 \mathrm{~h}$ to afford product $\mathrm{A}$. $\mathrm{In}_{2} \mathrm{O}_{3} \mathrm{HD}$ was obtained via the pyrolysis of the product $\mathrm{A}$ in an oxygen environment at $500{ }^{\circ} \mathrm{C}$ with a heating rate about $2^{\circ} \mathrm{C} \mathrm{min}{ }^{-1}$ for $6 \mathrm{~h}$.

Characterizations. The compositions and phases of the obtained samples were characterized by powder XRD on the PANalytical X'Pert diffractometer with a CuKa radiation. SEM (SU8100) and HRTEM (FEI Tecnai-F20) were used to characterize the shape and crystal structure. The surface compositions of samples were characterized by PHI QUANTUM2000 photoelectron spectrometer (XPS). $\mathrm{N}_{2}$ adsorption/desorption isotherms were used to characterize the surface areas of samples based on the BET method (Micrometrics ASAP 2020 system). Bruker ESP$300 \mathrm{E}$ spectrometer was used to measure EPR spectra at $9.8 \mathrm{GHz}$ with X-band and $100 \mathrm{~Hz}$ field modulation. Dynamic light scattering (DLS) experiments were conducted on a Nano-Zetasizer (Nano-ZS) from Malvern Instruments (Malvern, UK). The experimental process was as follows: samples $(0.1 \mathrm{~g})$ and ethanol $(10 \mathrm{~mL})$ were added into a glass bottle $(15 \mathrm{~mL})$ and dispersed uniformly by ultrasonication for $10 \mathrm{~min}$. Solutions were placed at different times under agitation and non-agitation, respectively. Then, the upper liquids were taken for DLS tests.

Photoelectrochemical measurements. Photoelectrochemical experiments were measured in the three electrode quartz cell. The Pt plate was selected as the counter electrode, the reference electrode was $\mathrm{Hg} / \mathrm{HgCl}_{2}$ electrode, and the corresponding working electrode was obtained on the fluorine doped tin oxide (FTO) glass. In order to obtain a slurry, the obtained product $(10 \mathrm{mg})$ was ultrasonicated in ethanol $(0.2 \mathrm{~mL})$. The slurry was then spread onto the FTO glass with the other side protected by using Scotch tape. After drying in air, the Scotch tape was unstuck. In order to improve the adhesion, the obtained working electrode with the area about $2.5 \mathrm{~cm}^{2}$ was dried at $300^{\circ} \mathrm{C}$ for $180 \mathrm{~min}$. The CHI-760E workstation was used to measure the EIS. In the three-electrode cell, the $0.025 \mathrm{M} \mathrm{KH}_{2} \mathrm{PO}_{4}$ and $0.025 \mathrm{M} \mathrm{Na}_{2} \mathrm{HPO}_{4}$ standard buffer solution $\left(25^{\circ} \mathrm{C}, \mathrm{pH}=6.864\right)$ were selected as the electrolytes without adding any additive, and the measurements were performed on an open circuit potential condition. A $300 \mathrm{~W}$ Xe arc lamp system was used as the visible-light irradiation source. The LSV technique was employed to obtain cathodic polarization curves.

Photocatalytic reactions. The photocatalyst $(5 \mathrm{mg})$, DIEA $(0.3 \mathrm{mmol})$, and phenylboronic acid $(0.1 \mathrm{mmol}, 1$ equivalent) were separately dissolved into ethanol $(2 \mathrm{~mL})$. The stirring solution was irradiated under the blue LED $(3 \mathrm{~W}, 450 \mathrm{~nm})$ at room temperature in air. The yield of the product was characterized by ${ }^{1} \mathrm{H}$ NMR spectra. To perform the recycling experiments, the photocatalyst was recovered by centrifugation and washed with dichloromethane for several times. The recycled photocatalyst was then dried in vacuum at about $60^{\circ} \mathrm{C}$ for $24 \mathrm{~h}$.

Density functional calculations. Plane-wave pseudopotential method was used to calculate the density functional, which was implemented in the Cambridge Sequential Total Energy Package (CASTEP) code ${ }^{59}$. The exchange-correlation effects and electron-ion interactions were described by the local density approximation $^{60}$ and ultrasoft pseudopotential ${ }^{61}$, respectively. A Morkhost-Pack mesh ${ }^{62}$ of $\Gamma$ and $2 \times 2 \times 1$ point were used to calculated geometry optimization and electronic properties, respectively. The self-consistent convergence accuracy, the convergence criterion for the force between atoms and the maximum displacement were set at $2 \times 10^{-6} \mathrm{eV} /$ atom, $5.5 \times 10^{-2} \mathrm{eV} / \AA$, and $2 \times 10^{-3} \AA$, respectively.

Reporting summary. Further information on research design is available in the Nature Research Reporting Summary linked to this article.

\section{Data availability}

The authors declare that the main data supporting the findings of this study are available within the paper and its Supplementary Information. The source data underlying Figs. 2, 3, 4, 5b-d and 6a-c and Supplementary Figs. 1a,i,q, 2a,b, 4, 5, 7-16, and 19-25 are provided as a Source Data file.

Received: 27 November 2018 Accepted: 29 April 2019

Published online: 22 May 2019

\section{References}

1. Prier, C. K., Rankic, D. A. \& Macmillan, D. W. C. Visible light photoredox catalysis with transition metal complexes: applications in organic synthesis. Chem. Rev. 113, 5322-5363 (2013).

2. Zhang, T. \& Lin, W. B. Metal-organic frameworks for artificial photosynthesis and photocatalysis. Chem. Soc. Rev. 43, 5982-5993 (2014).

3. Huo, H. H. et al. Asymmetric photoredox transition-metal catalysis activated by visible light. Nature 515, 100-103 (2014).

4. Ma, W. H., Chen, C. C., Ji, H. W. \& Zhao, J. C. Selective aerobic oxidation mediated by $\mathrm{TiO}_{2}$ photocatalysis. Acc. Chem. Res. 47, 355-363 (2014).

5. Davies, J., Svejstrup, T. D., Reina, D. F., Sheikh, N. S. \& Leonori, D. Visible-lightmediated synthesis of amidyl radicals: transition-metal-free hydroamination and n-arylation reactions. J. Am. Chem. Soc. 138, 8092-8095 (2016).

6. Chen, J. R., Hu, X. Q., Lu, L. Q. \& Xiao, W. J. Exploration of visible-light photocatalysis in heterocycle synthesis and functionalization: reaction design and beyond. Acc. Chem. Res. 49, 1911-1923 (2016).

7. Seo, H., Katcher, M. H. \& Jamison, T. F. Photoredox activation of carbon dioxide for amino acid synthesis in continuous flow. Nat. Chem. 9, 453-456 (2017).

8. Liu, Q. \& Wu, L. Z. Recent advances in visible-light-driven organic reactions. Natl. Sci. Rev. 4, 359-380 (2017).

9. Weng, W. -Z., Liang, H. \& Zhang, B. Visible-light-mediated aerobic oxidation of organoboron compounds using in situ generated hydrogen peroxide. Org. Lett. 20, 4979-4983 (2018).

10. Miyauchi, M., Nakajima, A., Watanabe, T. \& Hashimoto, K. Photocatalysis and photoinduced hydrophilicity of various metal oxide thin films. Chem. Mater. 14, 2812-2816 (2002).

11. Sun, M. et al. Enhanced photocatalytic oxygen evolution by crystal cutting. Adv. Mater. 25, 2035-2039 (2013)

12. Lei, F. C. et al. Oxygen vacancies confined in ultrathin indium oxide porous sheets for promoted visible-light water splitting. J. Am. Chem. Soc. 136, 6826-6829 (2014).

13. Hoch, L. B. et al. The rational design of a single-component photocatalyst for gas-phase $\mathrm{CO}_{2}$ reduction using both UV and Visible light. Adv. Sci. 1, 1400013 (2014).

14. Han, X. G. et al. Synthesis of trapezohedral indium oxide nanoparticles with high-index $\{211\}$ facets and high gas sensing activity. Chem. Commun. 51, 9612-9615 (2015)

15. He, L. et al. Spatial separation of charge carriers in $\operatorname{In}_{2} \mathrm{O}_{3-\mathrm{x}}(\mathrm{OH})_{\mathrm{y}}$ nanocrystal superstructures for enhanced gas-phase photocatalytic activity. ACS Nano 10, 5578-5586 (2016)

16. Hoch, L. B. et al. Effect of precursor selection on the photocatalytic performance of indium oxide nanomaterials for gas-phase $\mathrm{CO}_{2}$ reduction. Chem. Mater. 28, 4160-4168 (2016).

17. Gondal, M. A., Dastageer, M. A., Oloore, L. E., Baig, U. \& Rashid, S. G. Enhanced photo-catalytic activity of ordered mesoporous indium oxide nanocrystals in the conversion of $\mathrm{CO}_{2}$ into methanol. J. Environ. Sci. Heal. A 52, 785-793 (2017).

18. Zarghami, Z., Ramezani, M. \& Maddahfar, M. Facile hydrothermal synthesis, formation mechanism, and characterization of $\operatorname{In}(\mathrm{OH})_{3}$ nanostructures for preparation of $\operatorname{In}_{2} \mathrm{O}_{3}$ nanoparticles using novel starting reagents. J. Mater. Sci. Mater. El 26, 5884-5891 (2015).

19. Tian, J., Zhao, Z. H., Kumar, A., Boughton, R. I. \& Liu, H. Recent progress in design, synthesis, and applications of one-dimensional $\mathrm{TiO}_{2}$ nanostructured surface heterostructures: a review. Chem. Soc. Rev. 43, 6920-6937 (2014).

20. Zhao, L. et al. One-step solvothermal synthesis of a carbon@ $\mathrm{TiO}_{2}$ dyade structure effectively promoting visible-light photocatalysis. Adv. Mater. 22, 3317-3321 (2010).

21. Wu, G., Nishikawa, T., Ohtani, B. \& Chen, A. Synthesis and characterization of carbon-doped $\mathrm{TiO}_{2}$ nanostructures with enhanced visible light response. Chem. Mater. 19, 4530-4537 (2007).

22. Sakthivel, S. \& Kisch, H. Daylight photocatalysis by carbon-modified titanium dioxide. Angew. Chem. Int. Ed. 42, 4098-4911 (2003).

23. Pang, Q. et al. A nitrogen and sulfur dual-doped carbon derived from polyrhodanine@cellulose for advanced lithium-sulfur batteries. Adv. Mater. 27, 6021-6028 (2015). 
24. Qu, K. G., Zheng, Y., Dai, S. \& Qiao, S. Z. Graphene oxide-polydopamine derived N, S-codoped carbon nanosheets as superior bifunctional electrocatalysts for oxygen reduction and evolution. Nano Energy 19, 373-381 (2016).

25. Wang, F., Zhuo, H. Y., Han, X. G., Chen, W. M. \& Sun, D. Foam-like CoO@N, S-codoped carbon composites derived from a well-designed N,S-rich Co-MOF for lithium-ion batteries. J. Mater. Chem. A 5, 22964-22969 (2017).

26. Zhang, H., Lv, X. J., Li, Y. M., Wang, Y. \& Li, J. H. P25-graphene composite as a high performance photocatalyst. ACS Nano 4, 380-386 (2010).

27. Jeong, H. M. et al. Nitrogen-doped graphene for high-performance ultracapacitors and the importance of nitrogen-doped sites at basal planes. Nano Lett. 11, 2472-2477 (2011).

28. Xue, Y. et al. Low temperature growth of highly nitrogen-doped single crystal graphene arrays by chemical vapor deposition. J. Am. Chem. Soc. 134, 11060-11063 (2012)

29. Cui, X. et al. Pyridinic-nitrogen-dominated graphene aerogels with Fe-N-C coordination for highly efficient oxygen reduction reaction. Adv. Funct. Mater. 26, 5708-5717 (2016).

30. Wang, X. et al. Nitrogen and oxygen dual-doped carbon nanohorn for electrochemical capacitors. Carbon 118, 511-516 (2017).

31. Wang, L. et al. Photocatalytic hydrogenation of carbon dioxide with high selectivity to methanol at atmospheric pressure. Joule 2, 1369-1381 (2018).

32. Wang, L., Cai, M., Sun, W., He, L. \& Zhang, X. Promoting charge separation in semiconductor nanocrystal superstructures for enhanced photocatalytic activity. Adv. Mater. Interfaces 5, 1701694 (2018).

33. Jiang, H. L. et al. From metal-organic framework to nanoporous carbon: toward a very high surface area and hydrogen uptake. J. Am. Chem. Soc. 133, 11854-11857 (2011).

34. Zhao, D. et al. Highly efficient non-precious metal electrocatalysts prepared from one-pot synthesized zeolitic imidazolate frameworks. Adv. Mater. 26, 1093-1097 (2014).

35. Hu, L. \& Chen, Q. W. Hollow/porous nanostructures derived from nanoscale metal-organic frameworks towards high performance anodes for lithium-ion batteries. Nanoscale 6, 1236-1257 (2014).

36. Bai, Z. C. et al. MOFs-derived porous $\mathrm{Mn}_{2} \mathrm{O}_{3}$ as high-performance anode material for Li-ion battery. J. Mater. Chem. A 3, 5266-5269 (2015).

37. Xia, Y. et al. A metal-organic framework-derived bifunctional oxygen electrocatalyst. Nat. Energy 1, 15006 (2016).

38. Guo, W. X., Sun, W. W., Lv, L. P., Kong, S. F. \& Wang, Y. Microwave-assisted morphology evolution of Fe-based metal-organic frameworks and their derived $\mathrm{Fe}_{2} \mathrm{O}_{3}$ nanostructures for Li-Ion storage. ACS Nano 11, 4198-4205 (2017).

39. $\mathrm{Lu}, \mathrm{Y}$. Y. et al. MOF-templated synthesis of porous $\mathrm{Co}_{3} \mathrm{O}_{4}$ concave nanocubes with high specific surface area and their gas sensing properties. ACS Appl. Mater. Interfaces 6, 4186-4195 (2014).

40. Han, X., Chen, W. M., Han, X. G., Tan, Y. Z. \& Sun, D. Nitrogen-rich MOF derived porous $\mathrm{Co} 3 \mathrm{O} 4 / \mathrm{N}-\mathrm{C}$ composites with superior performance in lithium-ion batteries. J. Mater. Chem. A 4, 13040-13045 (2016).

41. Wu, F. F. et al. Unusual formation of $\mathrm{CoO} @ \mathrm{C}$ "dandelions" derived from 2D kagóme MOLs for efficient lithium storage. Adv. Energy Mater. 8, 1703242 (2018).

42. Chu, Y. T. et al. Embedding $\mathrm{MnO} @ \mathrm{Mn}_{3} \mathrm{O}_{4}$ nanoparticles in an N-dopedcarbon framework derived from Mn-organic clusters for efficient lithium storage. Adv. Mater. 30, 1704244 (2018).

43. Sun, L. M. et al. Rationally designed double-shell dodecahedral microreactors with efficient photoelectron transfer: N-doped-C-encapsulated ultrafine $\operatorname{In}_{2} \mathrm{O}_{3}$ nanoparticles. Chem. Eur. J. 25, 3053-3060 (2019).

44. Umemura, A. et al. Morphology design of porous coordination polymer crystals by coordination modulation. J. Am. Chem. Soc. 133, 15506-155513 (2011).

45. Tsuruoka, T. et al. Nanoporous nanorods fabricated by coordination modulation and oriented attachment growth. Angew. Chem. Int. Ed. 48, 4739-4743 (2009).

46. Hsieh, P. T. et al. Luminescence mechanism of $\mathrm{ZnO}$ thin film investigated by XPS measurement. Appl. Phys. A 90, 317-321 (2008).

47. Zhang, N., Yang, M. Q., Tang, Z. R. \& Xu, Y. J. Toward improving the graphene-semiconductor composite photoactivity via the addition of metal ions as generic interfacial mediator. ACS Nano 8, 623-633 (2014).

48. Quideau, S., Deffieux, D., Douat-Casassus, C. \& Pouysegu, L. Plant polyphenols: chemical properties, biological activities, and synthesis. Angew. Chem. Int. Ed. 50, 586-621 (2011).

49. Klepacka, J., Gujska, E. \& Michalak, J. Phenolic compounds as cultivar-and variety-distinguishing factors in some plant products. Plant Foods Hum. Nutr. 66, 64-69 (2011)

50. Nandi, S., Vracko, M. \& Bagchi, M. C. Anticancer activity of selected phenolic compounds: QSAR studies using ridge regression and neural networks. Chem. Biol. Drug Des. 70, 424-436 (2007)

51. Greenberg, M., Dodds, M. \& Tian, M. Naturally occurring phenolic antibacterial compounds show effectiveness against oral bacteria by a quantitative structure-activity relationship study. J. Agric. Food Chem. 56, 11151-11156 (2008)

52. Burton, G. W. et al. Autoxidation of biological molecules. 4. maximizing the antioxidant activity of phenols. J. Am. Chem. Soc. 107, 7053-7065 (1985).

53. Walsh, A. et al. Nature of the band gap of $\operatorname{In}_{2} \mathrm{O}_{3}$ revealed by first-principles calculations and x-ray spectroscopy. Phys. Rev. Lett. 100, 167402 (2008).

54. Zheng, C. X. et al. Selective photocatalytic oxidation of benzyl alcohol into benzaldehyde with high selectivity and conversion ratio over $\mathrm{Bi}_{4} \mathrm{O}_{5} \mathrm{Br}_{2}$ nanoflakes under blue LED irradiation. Appl. Catal. B 205, 201-210 (2017).

55. Luo, J., Zhang, X. \& Zhang, J. Carbazolic porous organic framework as an efficient, metal-free visible-light photocatalyst for organic synthesis. ACS Catal. 5, 2250-2254 (2015).

56. Chumakova, N. A. et al. Properties of graphite oxide powders and membranes as revealed by electron paramagnetic resonance spectroscopy. J. Phys. Chem. C. 122, 22750-22759 (2018).

57. Zhang, W. Q. et al. Robust metal-organic framework containing benzoselenadiazole for highly efficient aerobic cross-dehydrogenative coupling reactions under visible light. Inorg. Chem. 55, 1005-1007 (2016).

58. Su, C. et al. Probing the catalytic activity of porous graphene oxide and the origin of this behaviour. Nat. Commun. 3, 1298 (2012).

59. Clark, S. J. et al. First principles methods using CASTEP. Z. Krist. 220, 567 (2005).

60. Ceperley, D. M. \& Alder, B. J. Ground state of the electron gas by a stochastic method. Phys. Rev. Lett. 45, 566 (1980).

61. Rappe, A. M., Rabe, K. M., Kaxiras, E. \& Joannopoulos, J. D. Optimized pseudopotentials. Phys. Rev. B 41, 1227 (1990).

62. Monkhorst, H. J. \& Pack, J. Special points for brillouin-zone integrations. Phys. Rev. B 13, 5188 (1976).

\section{Acknowledgements}

This work was supported by the National Natural Science Foundation of China (21671085 and 21701063), the Jiangsu Province Science Foundation for Youths (BK20150237), the Natural Science Foundation of Jiangsu Province (BK20161160), the Qing Lan Project, and the Project Funded by the Priority Academic Program Development of Jiangsu Higher Education Institutions. It was also supported by the Singapore Agency for Science, Technology and Research (A`STAR) AME IRG grant (A1783c0007).

\section{Author contributions}

X.H. and Y.Z. conceived and designed the experiments and wrote the paper. L.S., R.L., and Y.Y. performed most of experiments and theoretical calculation. X.W. and W.Z. guided photocatalytic experiments. The manuscript was written through contributions of all authors. All authors have given approval to the final version of the manuscript.

\section{Additional information}

Supplementary Information accompanies this paper at https://doi.org/10.1038/s41467019-10302-0.

Competing interests: The authors declare no competing interests.

Reprints and permission information is available online at http://npg.nature.com/ reprintsandpermissions/

Journal peer review information: Nature Communications thanks Le He, Bo Zhang, and the other, anonymous, reviewer(s) for their contribution to the peer review of this work. Peer reviewer reports are available.

Publisher's note: Springer Nature remains neutral with regard to jurisdictional claims in published maps and institutional affiliations.

Open Access This article is licensed under a Creative Commons Attribution 4.0 International License, which permits use, sharing, adaptation, distribution and reproduction in any medium or format, as long as you give appropriate credit to the original author(s) and the source, provide a link to the Creative Commons license, and indicate if changes were made. The images or other third party material in this article are included in the article's Creative Commons license, unless indicated otherwise in a credit line to the material. If material is not included in the article's Creative Commons license and your intended use is not permitted by statutory regulation or exceeds the permitted use, you will need to obtain permission directly from the copyright holder. To view a copy of this license, visit http://creativecommons.org/ licenses/by/4.0/

(c) The Author(s) 2019 